\title{
Objective detection of long-term slow slip events along the Nankai Trough using GNSS data (1996-2016)
}

\author{
Akio Kobayashi* (i)
}

\begin{abstract}
This paper presents a method for objective detection of long-term slow slip events with durations on the order of years, on the plate boundary along the Nankai Trough, relying on global navigation satellite system daily coordinate data. The Chugoku region of Japan was held fixed to remove common mode errors, and a displacement component was calculated relative to the direction of plate subduction. Correlations were then calculated between this displacement component and a 3-year ramp function with a 1-year slope. Nearly all periods of strong correlation coincide with periods of previously reported long-term slow slip events. A period of strong correlation around the Kii Channel in 2000-2002 is attributed to a previously undocumented long-term slow slip event beneath the Kii Channel and the eastern part of Shikoku Island with an equivalent moment magnitude of 6.6. This detection method reveals variation among long-term slow slip events along the Nankai Trough.
\end{abstract}

Keywords: Long-term slow slip event, Nankai Trough, GNSS, Objective detection

\section{Background}

Aseismic slip phenomena known as slow earthquakes have been identified all over the world by analyzing data from the global navigation satellite system (GNSS) observation networks and high-sensitivity seismic observation networks. Slow earthquakes occur around locked fault zones that are considered likely to produce large earthquakes in the future, such as the Nankai Trough subduction plate boundary in southwest Japan. Short-term slow slip events (SSEs) with durations on the order of days accompanied by tremors and very low frequency (VLF) earthquakes, long-term SSEs with durations on the order of years, and shallow VLF earthquakes are observed along the Nankai Trough. Long-term SSEs are a type of slow earthquake, which occurs adjacent to the locked area of the Nankai Trough subduction zone, with magnitudes larger than other slow earthquakes (Obara 2011). During 2 decades of GNSS operation along the Nankai Trough, long-term SSEs have been repeatedly observed

\footnotetext{
*Correspondence: akobayas@mri-jma.go.jp
}

Meteorological Research Institute, 1-1 Nagamine, Tsukuba, Ibaraki 305-0052, Japan in the Bungo Channel west of Shikoku Island and in the Tokai region (Fig. 1). In the Bungo Channel, most of these long-term SSEs were nearly of equal magnitudes (Ozawa et al. 2013; Kobayashi and Yamamoto 2011), although smaller ones have also occurred (Ozawa 2017). In the Tokai region, the duration of the 2000-2005 longterm SSE (Suito and Ozawa 2009) was longer than those of earlier events detected by tide gauge and tiltmeter data (Kobayashi and Yoshida 2004; Yamamoto et al. 2005).

Radiguet et al. (2016) reported that an SSE began 2 months before the April 18, 2014, Papanoa earthquake in Mexico $\left(M_{w}\right.$ 7.3) at a location near the earthquake's source area, and they suggested that the SSE triggered the earthquake. Simulations of the seismic cycles of large interplate earthquakes based on a rate- and statedependent friction law include a model in which slipping during SSEs and stable sliding in deeper regions contribute to stress in the source areas of large earthquakes (Matsuzawa et al. 2010). Therefore, it is important to characterize the spatiotemporal transitions of long-term SSEs with uniform criteria, at least for the period of continuous GNSS observations. 
Nishimura et al. (2013) detected short-term SSEs along the Nankai Trough from GNSS data, using an objective method that detects offsets in GNSS time series accompanied by short-term SSEs by using the Akaike (1974) information criterion. However, as yet, there is no objective detection method for detecting long-term SSEs along the Nankai Trough. This paper describes such a method, which yields the spatiotemporal distribution of long-term SSEs along the Nankai Trough over 2 decades based on GNSS data.

\section{Methods}

\section{Improving GNSS daily coordinate data}

The method relies on the F3 daily coordinates (Nakagawa et al. 2009) of the GNSS Earth Observation Network System (GEONET), operated by the Geospatial Information Authority of Japan (GSI). The GNSS data dating back to March 1996 were reanalyzed by using the F3 strategy to obtain a consistent dataset of daily coordinates. Daily coordinates from March 1996 to June 2017 were used. In the GEONET F3 strategy (Nakagawa et al. 2009), global positioning system (GPS) data are analyzed with Bernese GPS Software version 5.0, and the final ephemerides of the International Global Navigation Satellite Systems Service (IGS) are used to estimate the static daily coordinates (Nishimura et al. 2013). The site coordinates of the GEONET stations are compared with those in the International Terrestrial Reference Frame (ITRF) 2005 by tightly constraining the coordinates of the IGS global sites to the a priori values of the ITRF 2005. The strategy includes the estimation of atmospheric delay gradients. Details can be found in Nakagawa et al. (2009) and Munekane (2010).

To extract unsteady crustal deformations, such as SSEs and afterslips, from the time series of the GNSS coordinates, time series $y(t)$ was modeled with the equation

$$
\begin{aligned}
y(t)= & A+B t+C \sin (2 \pi t / T)+D \cos (2 \pi t / T) \\
& +E \sin (4 \pi t / T)+F \cos (4 \pi t / T)+\sum_{i=1}^{N s} S_{i} H\left(t-t_{i}\right),
\end{aligned}
$$

where $y$ is the GNSS coordinate, $t$ is time, $A$ is the initial position, and $B$ is the steady-state or background velocity. The trigonometric functions represent annual and semiannual variations, $T=1$ year, and $C, D, E$, and $F$ are amplitudes. Ns is the number of displacement offsets with amplitude $S_{i}$ at time $t_{i}$ due to antenna/receiver replacement and earthquakes, and $H(t)$ is the Heaviside step function.

To estimate the steady-state or background velocity appropriately, it is necessary to exclude periods with unsteady phenomena from each station record. Unsteady events such as SSEs and postseismic deformations appear commonly in a certain range of areas. To simplify this step, Japan was divided into 13 blocks (Fig. 1), such that all stations of a particular block share the same history of unsteady phenomena. Then, the period for which to estimate the velocity of each block was selected (Table 1). Since postseismic deformation of the March 11, 2011 Tohoku earthquake ( $M$ 9.0) extends all over Japan, the period after the 2011 Tohoku earthquake is not used for estimation in any block. Some events affect only some of the stations in each block, but the periods were not modified for each station. This study relied on stations in the blocks of E, F, G, H, and I. Other blocks are not used here, but they are shown for reference. Furthermore, we checked the coordinate data and excluded periods which include unique unsteady deformations for each station, such as inadequate displacements due to the growth of trees around the antenna (Geodetic Observation Center 2004). The estimated steady-state velocity for each station was subtracted from the record for the entire period.

Offsets due to antenna replacements were subtracted by using an offset dataset provided by GSI [http://mekira. gsi.go.jp/JAPANESE/corrf3o.dat]. Coseismic offsets of large earthquakes (Table 2) were also removed, by calculating the difference in the 10-day means of the daily coordinates before and after each earthquake. The aim of this procedure is to remove the displacement associated with large earthquakes. This difference value may include initial postseismic deformation. If the scale of the earthquake is large, postseismic deformation will continue to appear. Two postseismic deformations affecting this analysis are corrected in a later procedure. For the summer 2000 seismic and volcanic event in the northern Izu Islands (Kaidzu et al. 2000), offsets were calculated by differencing the 10-day means before June 25, 2000, and after September 1, 2000. After subtracting these offsets, coefficients of annual and semiannual variations were estimated using the time series between March 1996 and February 2011 for each station, and the resulting variations were removed from the entire period.

GNSS coordinates include a spatially correlated "common mode" error (Wdowinski et al. 1997; Dong et al. 2006). Whereas a stable station is used as a fixed point in conventional analyses, it is difficult to find a stable point in the case of long-term analyses. Therefore, in this study, the common mode error of the Chugoku region (dotted rectangle in Fig. 1) was subtracted from the coordinates of all stations, in effect treating the entire Chugoku region as fixed. Chugoku region is close to the Nankai Trough and relatively stable without the influence of long-term SSEs. Although individual stations may contain small unstable displacements, fixing the entire Chugoku region is more stable than fixing a specific station. Specifically, the time series for each station in the Chugoku region 


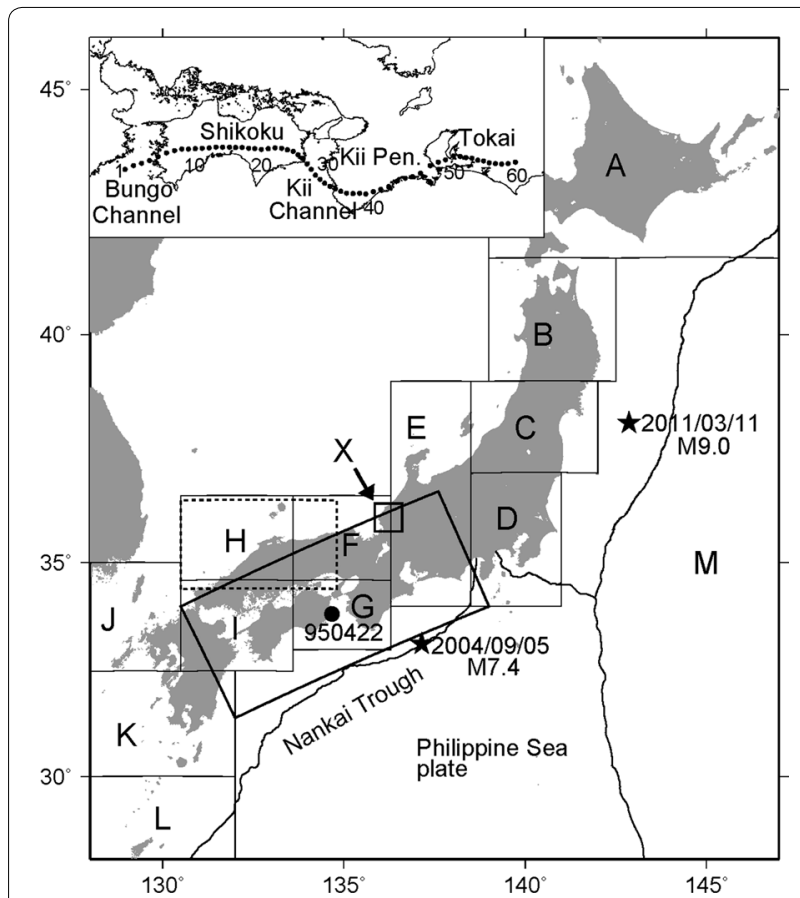

Fig. 1 Location map showing the study area and blocks used for steady-state velocity estimates. Solid curves indicate plate boundaries. The dotted rectangle encloses the Chugoku region. Labels $A$ to $M$ indicate blocks used for steady-state velocity estimation. Stars indicate earthquake epicenters, and the dot represents GNSS station 950422. The oblique rectangle is the Nankai Trough region shown in the inset map. Dots showing locations at $\sim 25 \mathrm{~km}$ depth on the Nankai Trough subduction interface

was obtained. Considering the possibility that the first value is an outlier, the median of the first 30 data values was set to zero. For stable stations, the time series after subtracting the steady-state velocity varies around zero. The median of the coordinates in the Chugoku region was calculated every day and that value was subtracted from the coordinates of all stations. Postseismic displacements of the 2011 Tohoku earthquake were observed at all analyzed stations, including those in the Chugoku region, and their amplitudes were dependent on stations. After removing the common mode error, the remaining postseismic deformations are relative to those in the Chugoku region. The results after this correction display a reduction in noise, particularly before 2000 (Fig. 2).

\section{Detection of long-term SSEs}

The long-term SSEs along the Nankai Trough are centered at a depth of $25-30 \mathrm{~km}$ on the Philippine Sea plate, and major surface displacements extend over a $100-\mathrm{km}$ square above the source region (e.g., Ozawa et al. 2002, 2013; Kobayashi 2014). The latitude of the $25-\mathrm{km}$ depth contour of the Philippine Sea plate (plate configuration of Hirose et al. 2008) in the Nankai Trough region (oblique rectangle in Fig. 1) was derived at intervals of $0.1^{\circ}$ from longitude $132.1^{\circ} \mathrm{E}$ to $138.0^{\circ} \mathrm{E}$, yielding a line of 60 points. A rectangle measuring $100 \mathrm{~km}$ in the direction of plate subduction (N55 ${ }^{\circ} \mathrm{W}$; Miyazaki and Heki 2001) and $50 \mathrm{~km}$ in width, closely matching the strike of the Nankai Trough, was centered on each of the 60 points, and data from the GNSS stations within each of these rectangles were extracted. The rectangles were specified as narrow in the along-strike direction to increase the resolution in that direction. Eleven stations with unstable displacement histories $(940065,950362,950364,950376,950447$, 960652, 021055, 031105, 031120, 041132, and 081172) were excluded from the analysis. These stations include periods that move differently from the surrounding stations. For each rectangle, the component of motion in the direction $\mathrm{S} 55^{\circ} \mathrm{E}$ was calculated, the opposite direction from plate subduction, from the mean of the horizontal components of the stations within the rectangle.

Displacement components obtained by this procedure included the postseismic deformations associated with the March 11, 2011 Tohoku earthquake (M 9.0) and the September 5, 2004 off Kii Peninsula earthquake (M 7.4). The postseismic deformation at stations along the Nankai Trough from the 2011 event through 2016 was dominated by the eastward component. Figure 3a shows a mean time series of east-west components after the 2011 Tohoku earthquake, normalized with respect to the maximum of the ten stations (940055, 950257, 950258, 950259, 950260, 960579, 960580, 020974, 020975, and 020977) within area $X$ in Fig. 1 . There are no unsteady displacements other than the postseismic deformation of the 2011 Tohoku earthquake during this period at these stations. Area $\mathrm{X}$ and the Tokai region are about the same distance from the earthquake source. This time series was approximated by a logarithmic function, assuming that the same time constant can be applied to the time series of displacement oriented $\mathrm{S} 55^{\circ} \mathrm{E}$, and the same logarithmic function was subtracted, fitting only the amplitude to the time series.

The correction procedure was similar for the 2004 event, for which the postseismic deformation overlapped the 2000-2005 long-term SSE in the Tokai region (Suito and Ozawa 2009). For the stations at which the postseismic deformation was dominant, according to Suito and Ozawa (2009), a mean time series of north-south components was calculated, normalized with respect to the maximum of eight stations close to the epicenter (940065, 940066, 950311, 950314, 950315, 950376, 960636, and 960637), from the date of the earthquake until December 2008 (Fig. 3b). Stations 940065 and 950376 were excluded from the analysis of unstable displacements, but these stations were considered in this analysis because no unstable displacements were seen in this period. The 
Table 1 Description of blocks (see Fig. 1) for estimating steady-state GNSS station velocities

\begin{tabular}{|c|c|c|c|}
\hline Block & Area & Steady period & Unsteady phenomena \\
\hline A & Hokkaido & 1996-1999, 2001-2002, 2009-2010 & $\begin{array}{l}\text { 01/28/2000 Nemuro-oki M7.0, } \\
\text { 09/26/2003 Tokachi-oki M8.0, } \\
\text { 11/29/2004 Kushiro-oki M7.1, } \\
\text { 12/06/2004 Kushiro-oki M6.9 }\end{array}$ \\
\hline B & Tohoku-N & 2001-2002, 2005-2007 & $\begin{array}{l}\text { 12/28/1994 Sanriku-haruka-oki M7.5, } \\
\text { 05/26/2003 Miyagi-oki M7.1, } \\
\text { 09/26/2003 Tokachi-oki M8.0, } \\
\text { 06/14/2008 Iwate-Miyagi-nairiku M7.2 }\end{array}$ \\
\hline C & Tohoku-S & 1996-2004 & $\begin{array}{l}\text { 08/16/2005 Miyagi-oki M7.2, } \\
\text { 07/16/2007 Niigata-ken Chuetsu-oki M6.8, } \\
\text { 05/08/2008 Ibaraki-oki M7.0 }\end{array}$ \\
\hline $\mathrm{D}$ & Kanto & 1996-1999, 2001-2003, 2005-2007, 2010 & $\begin{array}{l}\text { 2000 Izu-event, } \\
\text { 09/05/2004 off-Kii-Pen. M7.4, } \\
\text { 10/23/2004 Niigata-ken Chuetsu M6.8, } \\
\text { 05/08/2008 Ibaraki-oki M7.0 }\end{array}$ \\
\hline$E$ & Chubu & 1996-1999, 2006-2010 & $\begin{array}{l}\text { 2000-2005 Tokai LSSE, } \\
\text { 09/05/2004 off-Kii-Pen. M7.4 }\end{array}$ \\
\hline $\mathrm{F}$ & Kinki-N & 1996-2003, 2006-2008 & 09/05/2004 off-Kii-Pen. M7.4 \\
\hline G & Kii, Shikoku-E & 1998-2001, 2006-2010 & $\begin{array}{l}\text { 1996-1997 Kii Channel LSSE, } \\
\text { 2002-2003 Kii Channel LSSE, } \\
\text { 09/05/2004 off-Kii-Pen. M7.4 }\end{array}$ \\
\hline $\mathrm{H}$ & Chugoku-N & 1996-2008 & \\
\hline । & Shikoku-W, Kyushu-NE & 1998-2002, 2006-2008 & $\begin{array}{l}\text { 1996-1997 Bungo Channel LSSE, } \\
2003 \text { Bungo Channel LSSE, } \\
\text { 2009-2010 Bungo Channel LSSE, } \\
\text { 2005 western part of Shikoku LSSE, } \\
\text { 03/20/2005 Fukuoka-oki M7.0 }\end{array}$ \\
\hline J & Kyushu-NW & 1996-2009 & \\
\hline K & Kyushu-S & 2004-2009, 2012-2015 & $\begin{array}{l}\text { 10/19/1996 Hyuga-nada M6.9, } \\
\text { 03/26/1997 Kagoshima-ken Satsuma M6.6 }\end{array}$ \\
\hline L & Okinawa & 1996-2001, 2004-2015 & $\begin{array}{l}\text { 12/18/2001 Taiwan-oki M7.3, } \\
\text { 03/26/2002 Ishigaki-oki 7.0 }\end{array}$ \\
\hline M & Izu-Bonin & $1996-2015$ & \\
\hline
\end{tabular}

All: 03/11/2011 Tohoku-oki M9.0

LSSE long-term slow slip event

Table 2 Earthquakes affecting the study area during the study period

\begin{tabular}{lllllr}
\hline Date (JST) & M & Epicenter & Before & After & Stations \\
\hline June 25, 1997 & 6.6 & Yamaguchi & $06 / 24 / 1997(10)$ & $06 / 26 / 1997(10)$ & 5 \\
June-August 2000 & & northern Izu islands & $06 / 25 / 2000(10)$ & $09 / 01 / 2000(10)$ & 140 \\
October 6, 2000 & 7.3 & Tottori & $10 / 05 / 2000(10)$ & $10 / 07 / 2000(10)$ & 38 \\
March 24, 2001 & 6.7 & Geiyo & $03 / 23 / 2001(10)$ & $03 / 25 / 2001(10)$ & 65 \\
September 5, 2004 & 7.4 & off Kii Peninsula & $09 / 04 / 2004(10)$ & $09 / 07 / 2004(10)$ & 508 \\
March 20, 2005 & 7.0 & Fukuoka-oki & $03 / 19 / 2005(10)$ & $03 / 21 / 2005(10)$ & 44 \\
August 11, 2009 & 6.5 & Suruga bay & $08 / 09 / 2009(10)$ & $08 / 11 / 2009(10)$ & 125 \\
March 11, 2011 & 9.0 & Tohoku-oki & $03 / 10 / 2011(10)$ & $03 / 12 / 2011(2)$ & 123 \\
April 13, 2013 & 6.3 & Awaji & $04 / 11 / 2013(10)$ & $04 / 13 / 2013(10)$ & 187 \\
April 16, 2016 & 7.3 & Kumamoto & $04 / 13 / 2016(10)$ & $04 / 17 / 2016(2)$ & 19 \\
October 21, 2016 & 6.6 & Tottori & $10 / 20 / 2016(10)$ & $10 / 22 / 2016(10)$ & \\
\hline
\end{tabular}

Numbers in parentheses after the dates represent the number of days used for calculating the mean of the coordinates 
postseismic deformation at these stations was dominated by the southward component. The displacement time series for these stations was approximated by a logarithmic function; then, the corresponding amplitudes were subtracted from the displacement time series for a subset of the 60 aligned points. The time series for the 35 westernmost points were left unchanged because the postseismic amplitudes were negligible, and the easternmost 14 points, in the Tokai region, had also undergone displacement from the 2000-2005 SSE. Therefore, assuming that the postseismic displacement was proportional to the coseismic displacement, the amplitude coefficient was estimated from the north-south coseismic displacement based on the record for points 36 through 46, at longitudes $135.5^{\circ}-136.5^{\circ} \mathrm{E}$ (Fig. 3c). Figure 4 shows examples of the displacements in the $555^{\circ} \mathrm{E}$ direction before and after these corrections.

Here, the cross-correlation was considered between the displacement time series and a 3-year ramp function consisting of a linear slope over a 1 -year period that connects flat slopes in the previous and following years (Fig. 5). The ramp function had high correlation coefficients with three different displacement patterns: a step displacement in the middle of the 3-year period (0.94), steady displacement over 3 years (0.95), and steady displacement only during the third year (0.62) (Fig. 5). Thus, the chosen ramp function could encompass phenomena with durations shorter and longer than 1 year. However, the correlation coefficient is high even if there is a slightly positive linear trend because of the cross-correlation. Therefore, a condition was added in which the difference between the average of the latest one-third of the 3-year data and the average of the oldest one-third of the 3-year data is greater than $2 \mathrm{~mm}$. This difference usually corresponds to the displacement of a 2-year period. These conditions can detect long-term SSEs with durations of greater than 1 year and rates of greater than $1 \mathrm{~mm} /$ year. However, it is necessary to carefully remove the steady-state trends. The correlation coefficient between the corrected $S 55^{\circ} \mathrm{E}$ displacement and the ramp function was calculated every 3 days; that is, the correlation value for a given day was the correlation value between the ramp function and the data from 1.5 years before to 1.5 years after that day.

\section{Results and discussion}

\section{Spatiotemporal distribution of displacements}

The correlation between the displacement in the $555^{\circ} \mathrm{E}$ direction and the ramp function from March 1996 to December 2016 is graphed in time and space (Fig. 6). The results of 2017 are not shown, because the data period used for the correlation is short and the accuracy of the result is relatively low. The periods in which the correlation coefficient is greater than 0.6 and the 2-year displacement is greater than $2 \mathrm{~mm}$ are displayed. Each of the previously reported long-term SSEs along the Nankai Trough coincided with one of these periods.

In the Tokai area at longitudes $137^{\circ}-138^{\circ} \mathrm{E}$, the objective method identified displacements corresponding to the long-term SSEs in 2000-2005 (Ozawa et al. 2002; Suito and Ozawa 2009) and 2013 (Ozawa et al. 2016) that were documented by GNSS data (Fig. 6). As mentioned in the previous section, SSEs with greater than 1-year duration have also been successfully detected. The SSE that started in 2013 seems to have almost stopped by the end of 2016. In the Kii Channel near $135^{\circ} \mathrm{E}$, long-term SSEs in 1996-1997 (Kobayashi 2014) and 2014 (Meteorological Research Institute 2016) documented by GNSS data were corroborated by high correlation coefficients in Fig. 6. In
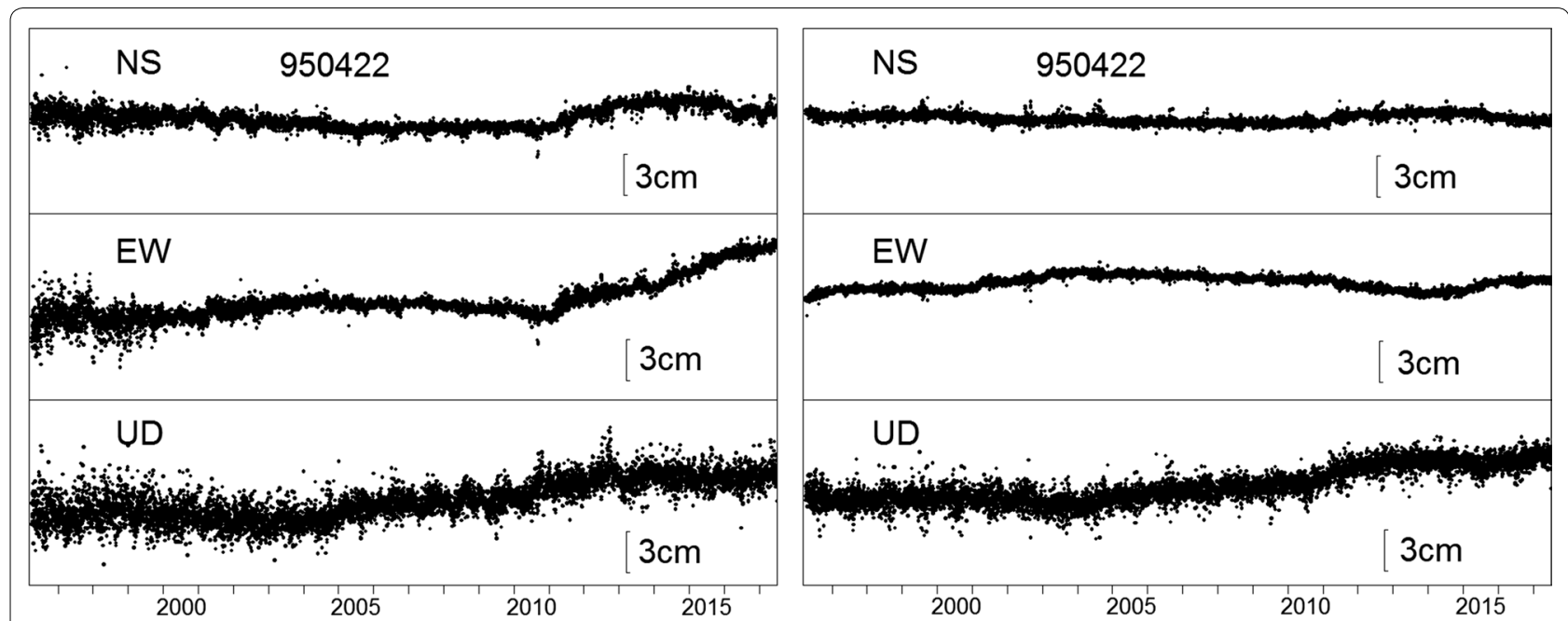

Fig. 2 GNSS daily coordinate time series for station 950422 before (left) and after (right) the common mode error correction. Station location is plotted in Fig. 1 
addition, there was a period of high correlation coefficients in 2000-2002 that is discussed in the next section. The SSE that started in 2014 seems to have declined by the end of 2016. Furthermore, in the Bungo Channel area at $132^{\circ}-133^{\circ} \mathrm{E}$, the long-term SSEs in 1996-1998 (Hirose et al. 1999), 2002-2004 (Ozawa et al. 2007), and 2010 (Ozawa et al. 2013) were matched by periods of high correlation values (Fig. 6). In addition, small long-term SSEs in western Shikoku in 2005 (Kobayashi 2010; Takagi et al. 2016) and in the Bungo Channel in 2014 (Ozawa 2017) appear in the figure. Takagi et al. (2016) also reported a small long-term SSE in western Shikoku in 2011-2013. It is not clearly detected in this method, but a slightly high correlation in central Shikoku around 2013 may correspond to this event.

The objective method revealed some of the spatiotemporal detail of these long-term SSEs. During the 1997 long-term SSE in the Bungo Channel, the center of the slip area moved southwest (Ozawa et al. 2007). The same progression appears in Fig. 6 in the area for which the correlation coefficient was greater than 0.9. No clear migration is seen for the 2002-2004 and 2010 SSEs in the Bungo Channel. It appears that this method, although incapable of detecting crustal deformation accompanying source migration in the direction of plate subduction, can detect deformation accompanying source migration orthogonal to subduction, to some extent.

The crustal deformation associated with seismic and volcanic activity in the northern Izu Islands from June to August 2000 extended into the Tokai area. However, this event nearly coincided with the long-term SSE in the Tokai area that began in 2000 (Miyazaki et al. 2006); therefore, the deformation caused by the northern Izu Islands event was not corrected here. The crustal deformation related to the SSE appears to have continued for some time, weakening after 2005 . This weakening may have resulted from the slow slip reaching the periphery of the source area before 2005 (Suito and Ozawa 2009), although it may possibly reflect postseismic deformation after the 2004 earthquake off Kii Peninsula.

\section{Slip distribution of the 2000-2002 long-term SSE in the Kii Channel}

Figure 6 shows evidence of a long-term SSE in the Kii Channel in 2000-2002, with a lower correlation value than that of the 2014 long-term SSE, which appears to have spread west during the latter part of that period. Horizontal unsteady displacement with respect to the fixed Chugoku region is seen from January 2000 to January 2003 (Fig. 7a). A change in displacement around the Kii Channel occurred between late 2000 and 2002 (Fig. 4b).
The unsteady displacement shows southeastward or eastward movements of up to $1 \mathrm{~cm}$ in eastern Shikoku and the western Kii Peninsula (Fig. 7a). There was no systematic unsteady displacement in the vertical component. This unsteady displacement event very likely corresponds to a long-term SSE on the plate boundary, because it continued for more than 2 years, the displacements were widely distributed, and no other events occurred during this period.

The slip vector on the plate interface was estimated using the inversion technique of Yabuki and Matsu'ura (1992), with some modifications (Naito and Yoshikawa 1999; Yamamoto 2005), based on the point source formulation of Okada (1992). The method of Yabuki and Matsu'ura (1992) represents the slip distribution and fault configuration as a superposition of B-spline functions. Slip vectors were estimated by using boxcar functions with a smoothness constraint for regularization. Smoothness values that minimized Akaike's Bayesian information criterion (ABIC, Akaike 1980) were considered. Slip vectors were calculated for a $16 \times 13$ grid of point sources on the plate interface and the plate interface configuration of Hirose et al. (2008). The grid intervals were about $11 \mathrm{~km}$ in the north-south direction and about $9 \mathrm{~km}$ in the east-west direction, and the slip was set to zero outside the grid. Dip and strike angles were derived from the plate configuration using continuous curvature splines in tension (Smith and Wessel 1990).

The estimated pattern of the slip distribution exhibited slips greater than $2 \mathrm{~cm}$ centered in the Kii Channel and eastern Shikoku (Fig. 7b). The centers of these slip patches were near a depth of $25 \mathrm{~km}$ on the plate boundary, slightly shallower than the depth of deep low-frequency earthquakes. The estimated moment magnitude of the total slip (exceeding the calculation error) was 6.6, assuming a rigidity of $40 \mathrm{GPa}$. Calculation errors lead to a range of 6.4-6.7. In comparison with the history of unsteady displacement shown in Fig. 6, there is a possibility that the slip occurred in the Kii Channel primarily in 2001 and then expanded westward to eastern Shikoku. However, the overall displacement was too small to estimate the slip for smaller divisions of the 2000-2002 period.

\section{Slip distribution of the 2014-2016 long-term SSE in the Kii Channel}

The horizontal displacement and slip distribution during the 2014-2016 long-term SSE in the Kii Channel are shown in Fig. 8, using data from January 2014 to January 2017. Stations in the central and northern Kii Peninsula were not used because they were influenced by the long-term SSE in the Tokai region, beginning in 2013. 

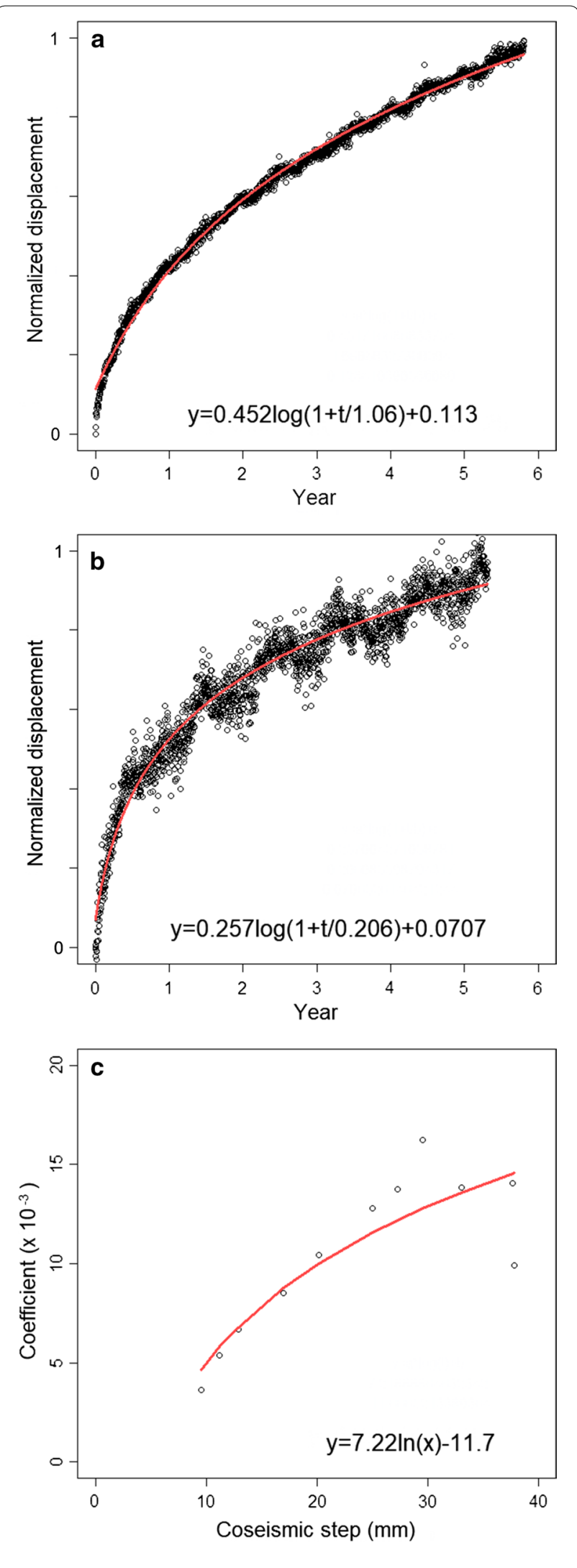

Fig. 3 Estimation of postseismic displacements. a Time series of EW components of postseismic deformation from the 2011 Tohoku earthquake, normalized with respect to the maximum of 10 stations within area $X$ in Fig. 1. $\mathbf{b}$ Time series of NS components of postseismic deformation from the 2004 earthquake off Kii Peninsula, normalized with respect to the maximum of a set of eight selected stations. c Correlation between the coseismic steps from the 2004 earthquake off Kii Peninsula and the amplitude coefficient of the fitted logarithmic function for points between $135.5^{\circ} \mathrm{E}$ and $136.5^{\circ} \mathrm{E}$. The red line in all plots is a curve fitted by a logarithmic function

The unsteady displacement of the event from 2014 was reduced by 2016 (Fig. 4b). Because the small size of the postseismic deformation associated with the 2011 Tohoku earthquake makes correcting station records in this region difficult, an alternative was considereddeducting the background velocity for the period January 2012 to December 2013 from each component. This correction yields an estimate of the SSE displacement as of January 2017 that is about 20\% greater than the displacement after correction, based on the logarithm function of Fig. 3a. However, the correction had little apparent influence on the estimated slip distribution.

Figure $8 \mathrm{~b}$ shows the slip distribution on the plate boundary as estimated from the displacement in Fig. 8a. The estimate was made by using an $18 \times 10$ grid of point sources on the plate interface. The center of maximum slip (4-5 cm) is located around a depth of $25 \mathrm{~km}$ beneath the Kii Channel. The total slip during the SSE represents an estimated moment magnitude of 6.7 (in excess of the calculation error), or 6.5-6.8 considering calculation errors.

\section{Variation of long-term SSEs along the Nankai Trough}

This section reviews the variation among the SSEs in the three segments of the study area: Bungo Channel, Kii Channel, and the Tokai region.

The long-term SSEs in the Bungo Channel in 1997, 2003, and 2010 produced nearly identical unsteady displacements (Fig. 6) and their slip distributions (Ozawa et al. 2013) were almost the same. Except for a small event in 2014, the Bungo Channel area experienced repeated long-term SSEs of the same scale at almost the same time interval. Leveling and tide gauge data also documented long-term SSEs that may have occurred around 1980, around 1985-1986, and around 1991 (Kobayashi and Yamamoto 2011). The repeat interval for these events is about 6 years, comparable to that found in this study.

The long-term SSE beneath the Kii Channel in 20142016 had the same scale and central position as the 1996-1997 long-term SSE (Kobayashi 2014). However, 

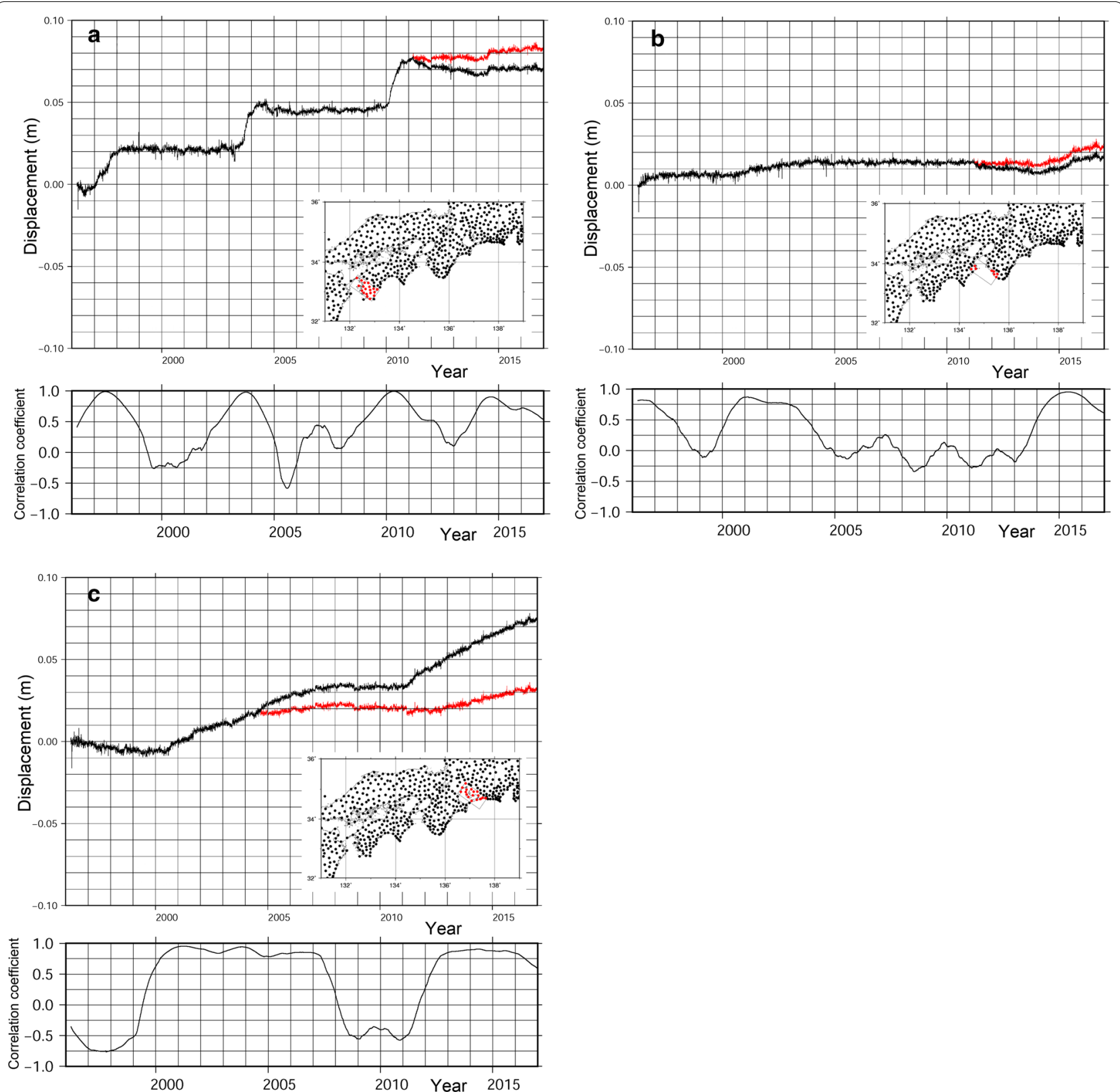

Fig. 4 Displacements in the direction $S 55^{\circ} \mathrm{E}$ (top) and correlation coefficients between the displacement and the ramp function at select points (bottom). a Bungo Channel and westernmost Shikoku. b Kii Channel. c Tokai region. Displacement is the mean of displacements of stations (red dots) within the $100 \mathrm{~km} \times 50 \mathrm{~km}$ rectangle on the inset map. Displacement curves after correcting for postseismic displacement are shown in red

the 2000-2002 long-term SSE was clearly smaller than the other two events and involved slipping in eastern Shikoku, whereby the other two events produced no slip. The intervals between these three events were about 4 years and more than 10 years. In sum, long-term SSEs beneath the Kii Channel were spatiotemporally variable.

Long-term SSEs in the Tokai region in 2000-2005 and 2013 produced the unsteady displacements shown in Fig. 6. Earlier long-term SSEs occurred in 1980-1982 and 1988-1990 as documented by leveling, tide gauge, and tiltmeter data (Kobayashi and Yoshida 2004; Nagoya University 2004; Yamamoto et al. 2005). The unsteady displacement of the 2013 event was reduced by 2016 (Fig. 4c). The duration of the 2000-2005 event is exceptionally long. Crustal deformations in this region due to the northern Izu Islands event were smaller than 

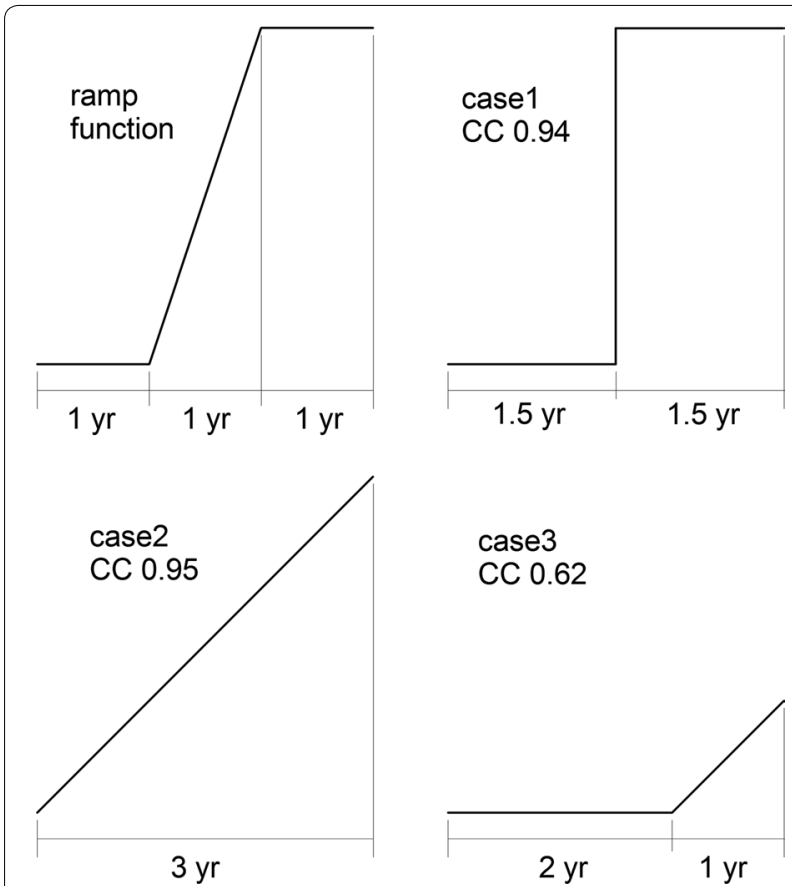

case 3

CC 0.62

Fig. 5 Ramp function and examples of cross-correlation. The ramp function at the upper left is the one used in this study, and the other plots are examples of displacement time series showing their correlation coefficient (CC) with respect to the ramp function
$1 \mathrm{~cm}$ over a period of 3 months (Kaidzu et al. 2000). It is unclear whether the 2000-2005 long-term SSE was prolonged by the influence of this event.

Within the study period, there were no unsteady displacements related to the sources of long-term slow slip on the plate boundary beneath the Kii Peninsula and central Shikoku. No long-term SSE was detected in the Kii Peninsula from 1980 to 2009 (Kobayashi 2013), and leveling and tide gauge data suggest a possible long-term SSE from 1977 to 1980 in central Shikoku (Kobayashi 2012). In summary, long-term SSEs are not homogeneous along the strike direction of the Nankai Trough. Locally, SSEs appear to recur with the same scale and time interval in the Bungo Channel, and events in the Kii Channel vary in time and space.

Matsuzawa et al. (2010) modeled the long- and shortterm SSEs in the seismic cycles for the Nankai region, indicating that the recurrence intervals of both types of SSEs decrease in the later stages of interseismic periods. Regarding the recent earthquakes, a long-term SSE had occurred beginning 8 months prior to the $2014 \mathrm{M}_{\mathrm{w}} 8.1$ Iquique earthquake of Chile (Socquet et al. 2017), and a 5-month-long SSE migrated toward the $2012 \mathrm{M}_{\mathrm{w}} 7.4$ Ometepec earthquake of Mexico (Colella et al. 2017). These examples indicate that long-term SSEs and large

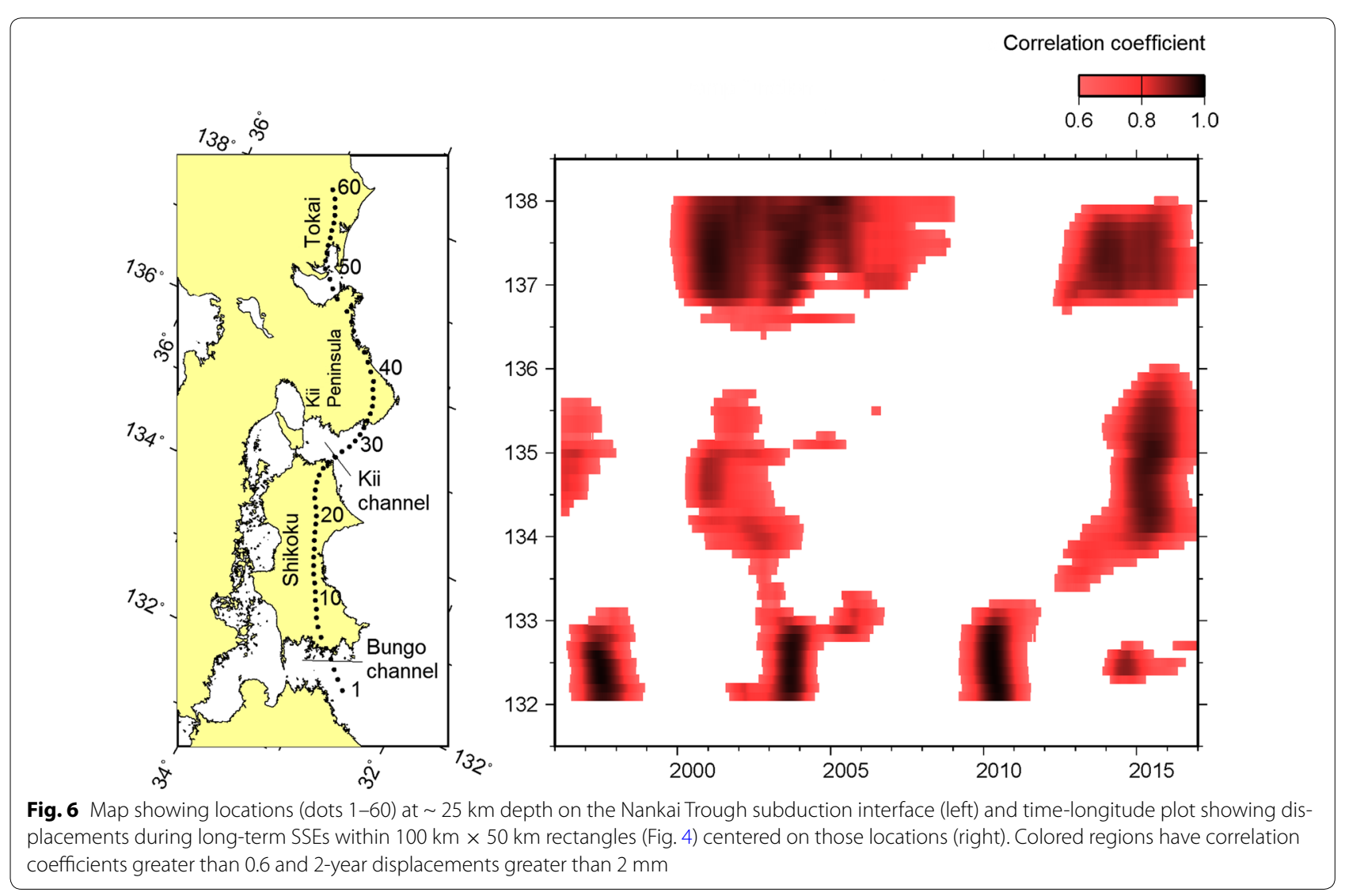



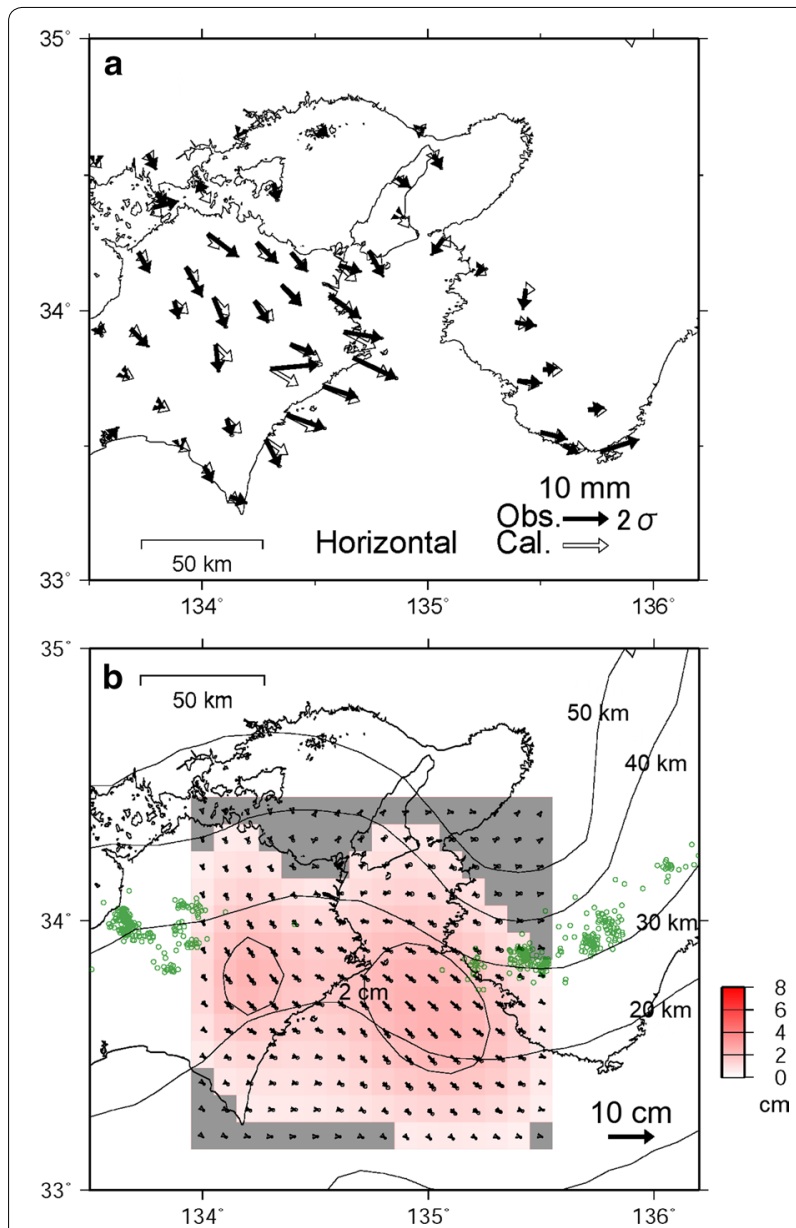

Fig. 7 Horizontal unsteady displacements and estimated slip distribution in eastern Shikoku and Kii Channel for the period January 2000 to January 2003. a Horizontal displacements used for estimating slip. Black arrows indicate observations, and white arrows indicate calculated values. Ellipses at the top of arrows indicate $2 \sigma$ errors inferred from standard deviations of coordinates over a 1-month period. $\mathbf{b}$ Estimated slip distribution. Slip arrows indicate the motion of the overriding plate with respect to the subducting Philippine Sea plate. Small circles at the tips of arrows indicate the estimation errors. Gray shading indicates the area where the slip amount is smaller than the error. Green circles indicate epicenters of deep low-frequency earthquakes from January 2000 to January 2003 of the Japan Meteorological Agency earthquake catalog. Contours show the depth of the top of the subducting Philippine Sea plate (Hirose et al. 2008)

earthquakes are closely related to each other, suggesting the importance of monitoring the spatiotemporal distribution of long-term SSEs and its change.

\section{Notes on the objective method}

The reliance of this method on a ramp function may affect correlations at the start and end of the period of record. Even if a displacement is steady, the correlation becomes lower because this method requires data for 1.5 years out of the 3 years. For instance, the correlation
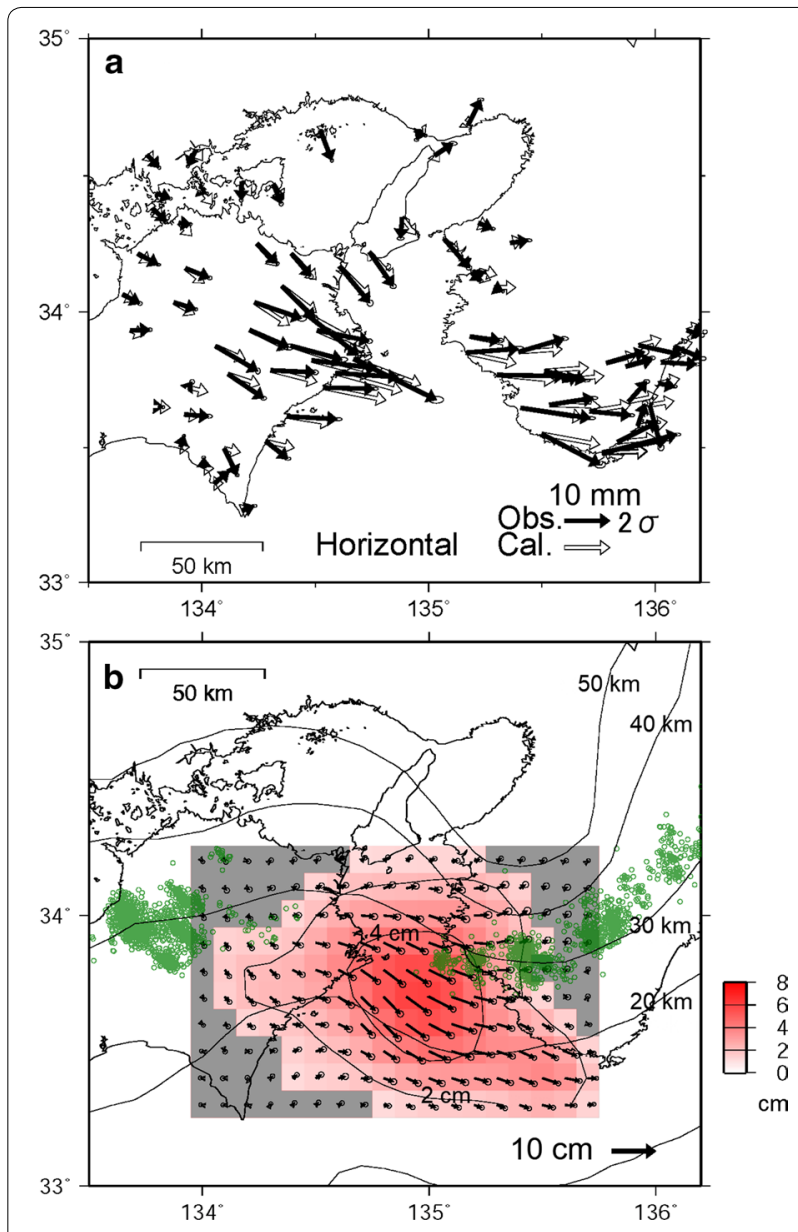

Fig. 8 Horizontal displacements and estimated slip distribution in eastern Shikoku and Kii Channel for the period January 2014 to January 2017. a Horizontal displacements used for estimating slip. b Estimated slip distribution. Green circles indicate epicenters of deep low-frequency earthquakes from January 2014 to January 2017. Symbols are the same as in Fig. 7

value of the long-term SSEs in the Tokai region and the Kii Channel was lower for 2016. The actual displacement record (Fig. 4) must be consulted to determine whether the decrease was an artifact of this method. Also, a clear positive change in any part of the 3-year period for which the correlation value is calculated increases the correlation for the entire period, beyond the time during which the actual phenomenon occurs. For example, case 3 in Fig. 5 shows that the method produces a correlation value of 0.62 before the phenomenon even begins.

It should be noted that high correlations are related to the horizontal displacement of the ground surface, rather than the slip on the plate boundary. The area of displacement on the plate boundary is generally narrower than the area of high correlation, because horizontal displacement appears over a large area on the ground, even when the slip at depth occurs in a narrow region. 
Modeling of postseismic deformation for the time series of individual coordinate values is often conducted. The estimated coefficients are appropriate when the amplitude of the postseismic deformation is large, but the estimation error increases when the amplitude is small. For example, the amplitude of the postseismic deformation of north-south and east-west components in Shikoku within a year after the 2011 Tohoku earthquake is less than $1 \mathrm{~cm}$. In this study, in order to avoid cumulative modeling errors of postseismic deformations estimated from individual coordinate values, parameters of postseismic deformations were estimated after synthesizing the components of the stations within the rectangles, excluding the common mode error.

A correlation value with a 3-year ramp function and a 2-year displacement was used in this study to determine the conditions of long-term SSEs. As already mentioned, linear trends affect these conditions, so eliminating appropriate linear trends from individual coordinate values is important. For more objective detection of longterm SSEs, this linear trend removal process is useful under certain conditions.

When ramp functions with slope periods of 0.5 and 0.3 years were tested, no new areas of high correlation were found in the study area. This method can be applied to short-term SSEs by using shorter ramp functions, but that topic was not addressed in this study. Although this study was conducted along the Nankai Trough, similar methods can be applied to other areas where long-term SSEs have been reported.

\section{Conclusions}

An objective method for detecting long-term SSEs was tested using GNSS daily coordinate data along the Nankai Trough. The events detected closely matched the periods of previously reported long-term SSEs. A previously unreported period of unsteady displacement was detected around the Kii Channel in 2000-2002, representing the release of energy equivalent to a $M_{w} 6.6$ earthquake beneath the Kii Channel and eastern Shikoku. During the study period, events in the Bungo Channel occurred with consistent scales and regular timing, whereas events in the Kii Channel had different scales and occurrence intervals. In summary, long-term SSEs along the Nankai Trough vary in their spatial and temporal properties. When evaluating the slip distribution on the plate boundary, the influence of SSEs must be considered in models of the seismogenic region of the megathrust.

\section{Abbreviations}

GNSS: Global navigation satellite system; GPS: Global positioning system; SSE: Slow slip event; VLF: Very low frequency; M: Magnitude; $M_{w}$ : Moment magnitude.

\section{Acknowledgements}

The GNSS F3 coordinate data and offset data were provided by the Geospatial Information Authority of Japan. MICAP-G software (Naito and Yoshikawa 1999; Yamamoto 2005) based on the formulation of Okada (1992) was used for estimating slip distribution, and GMT software (Wessel and Smith 1998) was used for drafting figures. I thank two anonymous reviewers and the editor Takuya Nishimura for their careful and constructive reviews. I thank F. Hirose and T.

Yamamoto for providing suggestions that improved the manuscript.

\section{Competing interests}

The author declares that he has no competing interests.

\section{Ethics approval and consent to participate}

Not applicable.

\section{Publishers' Note}

Springer Nature remains neutral with regard to jurisdictional claims in published maps and institutional affiliations.

Received: 6 July 2017 Accepted: 6 December 2017 Published online: 21 December 2017

\section{References}

Akaike H (1974) A new look at the statistical model identification. IEEE Trans Autom Control 19:716-723. https://doi.org/10.1109/TAC.1974.1100705

Akaike H (1980) Likelihood and the Bayes procedure. In: Bernard JM, DeGroot MH, Lindley DV, Smith AFM (eds) Bayesian statistics. University Press, Valencia, pp 143-166

Colella HV, Sit SM, Brudzinski MR, Graham SE, DeMets C, Holtkamp SG, Skoumal RJ, Ghouse N, Cabral-Cano E, Kostoglodev V, Arciniega-Ceballos A (2017) Seismicity rate increases associated with slow slip episodes prior to the $2012 M_{w} 7.4$ Ometepec earthquake. Earth Planet Sci Lett 464:35-45. https://doi.org/10.1016/j.epsl.2016.12.032

Dong D, Fang P, Bock Y, Webb F, Prawirodirdjo L, Kedar S, Jamason P (2006) Spatiotemporal filtering using principal component analysis and Karhunen-Loeve expansion approaches for regional GPS network analysis. J Geophys Res 111:B03405. https://doi.org/10.1029/2005JB003806

Geodetic Observation Center (2004) Establishment of the nationwide observation system of 1,200 GPS-based control stations. J Geogr Surv Inst 103:1-51 (in Japanese)

Hirose H, Hirahara K, Kimata F, Fujii N, Miyazaki S (1999) A slow thrust slip event following the two 1996 Hyuganada earthquakes beneath the Bungo Channel, southwest Japan. Geophys Res Lett 26:3237-3240. https://doi. org/10.1029/1999GL010999

Hirose F, Nakajima J, Hasegawa A (2008) Three-dimensional seismic velocity structure and configuration of the Philippine Sea slab in southwestern Japan estimated by double-difference tomography. J Geophys Res 113:B09315. https://doi.org/10.1029/2007JB005274

Kaidzu M, Nishimura T, Murakami M, Ozawa S, Sagiya T, Yarai H, Imakiire $T$ (2000) Crustal deformation associated with crustal activities in the northern Izu-islands area during the summer, 2000. Earth Planets Space 52:ix-xviii. https://doi.org/10.1186/bf03351658

Kobayashi A (2010) A small scale long-term slow slip occurred in the western Shikoku in 2005. J Seismol Soc Jpn 63:97-100. https://doi.org/10.4294/ zisin.63.97 (in Japanese)

Kobayashi A (2012) Long-term slow slip event around Kochi City from 1977 to 1980. J Seismol Soc Jpn 64:63-73. https://doi.org/10.4294/Zisin.64.63 (in Japanese)

Kobayashi A (2013) Vertical crustal deformation in the Kii Peninsula deduced from leveling and sea-level data, 1972-2009. J Seismol Soc Jpn 66:15-25. https://doi.org/10.4294/zisin.66.15 (in Japanese)

Kobayashi A (2014) A long-term slow slip event from 1996 to 1997 in the Kii Channel, Japan. Earth Planets Space 66:9. https://doi. org/10.1186/1880-5981-66-9

Kobayashi A, Yamamoto T (2011) Repetitive long-term slow slip events beneath the Bungo Channel, southwestern Japan, identified from 
leveling and sea level data from 1979 to 2008. J Geophys Res 116:B04406. https://doi.org/10.1029/2010JB007822

Kobayashi A, Yoshida A (2004) Recurrence of the Tokai slow slip inferred from the tide gauge data at Maisaka. J Geod Soc Jpn 50:209-212. https://doi. org/10.11366/sokuchi1954.50.209 (in Japanese with English abstract)

Matsuzawa T, Hirose H, Shibazaki B, Obara K (2010) Modeling short- and long-term slow slip events in the seismic cycles of large subduction earthquakes. J Geophys Res 115:B12301. https://doi. org/10.1029/2010JB007566

Meteorological Research Institute (2016) Baseline length changes perpendicular to the trench axes in Japan. Report Coord Comm Earthq Predict 95:26-31 (in Japanese)

Miyazaki S, Heki K (2001) Crustal velocity field of southwest Japan: subduction and arc- collision. J Geophys Res 106:4305-4326. https://doi. org/10.1029/2000JB900312

Miyazaki S, Segall P, McGuire JJ, Kato T, Hatanaka Y (2006) Spatial and temporal evolution of stress and slip rate during the 2000 Tokai slow earthquake. J Geophys Res 111:B03409. https://doi.org/10.1029/2004JB003426

Munekane H (2010) On improving precision of GPS-derived height time series at GEONET stations. Bull GSI 58:39-46

Naito H, Yoshikawa S (1999) A program to assist crustal deformation analysis. J Seismol Soc Jpn 52:101-103 (in Japanese)

Nakagawa H, Toyofuku T, Kotani K, Miyahara B, Iwashita C, Kawamoto S, Hatanaka Y, Munekane H, Ishimoto M, Yutsudo T, Ishikura N, Sugawara Y (2009) Development and validation of GEONET new analysis strategy (Version 4). J Geogr Surv Inst 118:1-8 (in Japanese)

Nishimura T, Matsuzawa T, Obara K (2013) Detection of short-term slow slip events along the Nankai Trough, southwest Japan, using GNSS data. J Geophys Res. https://doi.org/10.1002/jgrb.50222

Obara K (2011) Characteristics and interactions between non-volcanic tremor and related slow earthquakes in the Nankai subduction zone, southwest Japan. J Geodyn 52:229-248. https://doi.org/10.1016/j.jog.2011.04.002

Okada Y (1992) Internal deformation due to shear and tensile faults in a halfspace. Bull Seismol Soc Am 82(2):1018-1040

Ozawa S (2017) Long-term slow slip events along the Nankai trough subduction zone after the 2011 Tohoku earthquake in Japan. Earth Planets Space 69:56. https://doi.org/10.1186/s40623-017-0640-4

Ozawa S, Murakami M, Kaidzu M, Tada T, Sagiya T, Hatanaka Y, Yarai H, Nishimura T (2002) Detection and monitoring of ongoing aseismic slip in the Tokai region, central Japan. Science 298:1009-1012. https://doi. org/10.1126/science. 1076780

Ozawa S, Suito H, Imakiire T, Murakmi M (2007) Spatiotemporal evolution of aseismic interplate slip between 1996 and 1998 and between 2002 and 2004, in Bungo channel, southwest Japan. J Geophys Res 112:B05409. https://doi.org/10.1029/2006JB004643
Ozawa S, Yarai H, Imakiire T, Tobita M (2013) Spatial and temporal evolution of the long-term slow slip in the Bungo Channel, Japan. Earth Planets Space 65:67-73. https://doi.org/10.5047/eps.2012.06.009

Ozawa S, Tobita M, Yarai H (2016) A possible restart of an interplate slow slip adjacent to the Tokai seismic gap in Japan. Earth Planets Space 68:54. https://doi.org/10.1186/s40623-016-0430-4

Radiguet M, Perfettini H, Cotte N, Gualandi A, Valette B, Kostoglodov V, Lhomme T, Walpersdorf A, Cabral Cano E, Campillo M (2016) Triggering of the $2014 M_{w} 7.3$ Papanoa earthquake by a slow slip event in Guerrero, Mexico. Nat Geosci 9:829-833. https://doi.org/10.1038/NGEO2817

Smith WHF, Wessel P (1990) Gridding with continuous curvature splines in tension. Geophysics 55:293-305. https://doi.org/10.1190/1.1442837

Socquet A, Valdes JP, Jara J, Cotton F, Walpersdorf A, Cotte N, Specht S, OrtegaCulaciati F, Carrizo D, Norabuena E (2017) An 8 month slows lip event triggers progressive nucleation of the 2014 Chile megathrust. Geophys Res Lett 44:4046-4053. https://doi.org/10.1002/2017GL073023

Suito H, Ozawa S (2009) Transient crustal deformation in the Tokai district-The Tokai slow slip event and postseismic deformation caused by the 2004 off southeast Kii peninsula earthquake. J Seismol Soc Jpn 61:113-135. https://doi.org/10.4294/zisin.61.113 (in Japanese with English abstract)

Takagi R, Obara K, Maeda T (2016) Slow slip event within a gap between tremor and locked zones in the Nankai subduction zone. Geophys Res Lett 43:1066-1074. https://doi.org/10.1002/2015GL066987

University Nagoya (2004) Ground deformation and estimated inter plate coupling in Tokai region detected by leveling, tide gage measurements and GPS measurements for last 20 years since 1980 to 2003. Report Coord Comm Earthq Predict 72:424-430 (in Japanese)

Wdowinski S, Bock Y, Zhang J, Fang P, Genrich J (1997) Southern California Permanent GPS Geodetic Array: spatial filtering of daily positions for estimating coseismic and postseismic displacements induced by the 1992 Landers earthquake. J Geophys Res 102:18057-18070. https://doi. org/10.1029/97JB01378

Wessel P, Smith WHF (1998) New, improved version of the Generic Mapping Tools released. EOS Trans Am Geophys Union 79:579. https://doi. org/10.1029/98EO00426

Yabuki T, Matsu'ura M (1992) Geodetic data inversion using a Bayesian information criterion for spatial distribution of fault slip. Geophys J Int 109:363-375. https://doi.org/10.1111/j.1365-246X.1992.tb00102.x

Yamamoto T (2005) Development of a software to assist crustal deformation analysis. Tech Rep Meteorol Res Inst 46:156-159 (in Japanese)

Yamamoto E, Matsumura S, Ohkubo T (2005) A slow slip event in the Tokai area detected by tilt and seismic observation and its possible recurrence. Earth Planets Space 57:917-923. https://doi.org/10.1186/BF03351871

\section{Submit your manuscript to a SpringerOpen ${ }^{\odot}$ journal and benefit from:}

- Convenient online submission

- Rigorous peer review

- Open access: articles freely available online

- High visibility within the field

- Retaining the copyright to your article

Submit your next manuscript at $\boldsymbol{\nabla}$ springeropen.com 